\title{
A IMPLEMENTAÇÃO DE MARKETING DE SERVIÇOS NA CAPTAÇÃO DE NOVOS CLIENTES: ESTUDO DE CASO NA EMPRESA TRANSLINS TRANSPORTES
}

\section{ARTIGO ORIGINAL}

DANTAS, Ayrton Luan Andrade1, LOPES, Mariana Caroline Monteiro², TOLEDANO, Klévia Vitória Soares ${ }^{3}$, ROBERTO, José Carlos Alves ${ }^{4}$, SANTOS JÚNIOR, Aldemir Pereira dos ${ }^{5}$, ALMEIDA, Victor da Silva $^{6}$

DANTAS, Ayrton Luan Andrade. Et al. A implementação de marketing de serviços na captação de novos clientes: estudo de caso na Empresa Translins Transportes. Revista Científica Multidisciplinar Núcleo do Conhecimento. Ano 06, Ed. 11, Vol. 03, pp. 41-62. Novembro de 2021. ISSN: 2448-0959, Link de acesso: https://www.nucleodoconhecimento.com.br/administracao/captacao-de-novos, DOI: 10.32749/nucleodoconhecimento.com.br/administracao/captacao-de-novos

\section{RESUMO}

Considerando as mudanças mercadológicas, onde é necessário empenhar-se diariamente para captar novos clientes e subsistir no mercado, a figura do Marketing de Serviços apresenta-se como uma alternativa viável. Destarte, este estudo pretende discutir: Como o Marketing de Serviços impacta na captação de clientes? O presente artigo teve como escopo realizar um estudo de caso na Translins Transportes, empresa de pequeno porte atuante na área de logística. Seu objetivo

\footnotetext{
${ }^{1}$ Graduando do curso de Administração.

${ }^{2}$ Graduando do curso de Administração.

${ }^{3}$ Graduando do curso de Administração.

${ }^{4}$ Orientador. Mestre em Engenharia de produção. Especialista em Logística empresarial. Graduado em Administração com Ênfase em Marketing.

${ }^{5}$ Coorientador. Mestre em Ciências do Ambiente e Sustentabilidade na Amazônia. Especialista em Gestão dos Recursos Naturais e Meio Ambiente. Especialista em Metodologia do Ensino Superior. Graduado em Turismo e Administração.

${ }^{6}$ Coorientador. Mestre em Engenharia de Processos. Pós-Graduando em Neuropsicopedagogia Institucional. Especialista em Gestão Estratégica de RH. Graduado em Administração e Pedagogia.
}

RC: 100657

Disponível em: https://www.nucleodoconhecimento.com.br/administracao/captacaode-novos 
geral consistiu em projetar como o emprego de Marketing de Serviços e uso de CRM impactam na captação de novos clientes. A metodologia empregada foi pesquisa de campo, estudo de caso e produção bibliográfica. $\mathrm{O}$ artigo surgiu a partir de estudos da análise das áreas funcionais, onde identificou-se a área de Marketing como a mais crítica, sendo o alvo da proposta de intervenção. As ferramentas interventivas utilizadas foram Diagrama de Ishikawa, $5 \mathrm{~W} 2 \mathrm{H}$ e Análise SWOT. Espera-se que com a introdução das ações interventivas passe a existir controle de fluxo de clientes, controle de satisfação deles com os serviços prestados e, ainda, aumento na quantidade de clientes contratando a Translins Transportes.

Palavras-chave: marketing, serviços; comunicação, consumidor, captação de clientes.

\section{INTRODUÇÃO}

O presente artigo se baseia em um estudo bibliográfico que objetiva demonstrar a importância do Marketing de Serviços na captação de novos clientes, e comprova a teoria aplicando-a em um estudo de caso, feito a partir do diagnóstico organizacional da Translins Transportes, empresa de pequeno porte.

Esta pesquisa objetivou abranger conceitos básicos, como os de Marketing e Serviço, para então compreender como estas técnicas se relacionam com os problemas abordados na empresa que foi alvo do estudo de caso. Compreendidos os conceitos basilares ainda na Fundamentação Teórica, durante o estudo de caso que foi alvo de "Análise e Discussão", ocorreu a aplicação das ferramentas de qualidade que deram base ao desenvolvimento destes.

Considerando que o problema da pesquisa está relacionado a captação de clientes, conforme Nascimento (2016, p. 01) bem determina, a pergunta problema é a questão que poderá ser resolvida através da pesquisa. Neste caso, a que foi eleita é: como o Marketing de Serviços pode influenciar na captação de novos clientes? Uma vez que a área mais crítica da empresa é o setor de Marketing. 
Para responder ao questionamento foi elaborada uma pesquisa aplicada de natureza descritiva e qualitativa (NASCIMENTO, 2016), utilizando-se também das ferramentas: Diagrama de Ishikawa, Análise SWOT e 5W2H para compreender as raízes dos pontos críticos verificados no diagnóstico da Translins Transportes. Quanto aos fins, a pesquisa tem natureza exploratória e quanto aos meios, destacase a pesquisa de campo, estudo de caso e produção bibliográfica.

Nestes termos, o esperado para este estudo é compreender como o Marketing de Serviços, enquanto proposta de CRM, se aplicaria na Translins Transportes para promover efetiva captação de clientes, apresentando os pontos críticos da empresa com o propósito de solucioná-los a partir da adoção de técnicas deste tipo de Marketing.

\section{FUNDAMENTAÇÃO TEÓRICA}

\subsection{CONCEITOS BASILARES DE MARKETING E MARKETING DE SERVIÇOS}

Conforme incipientemente abordado, o Marketing é a ciência responsável por estudar meios de fomentar no consumidor o anseio pelos produtos ou serviços de determinada empresa (ROCHA e PLATT, 2015, p. 03), sendo evidente que o Marketing não se limita apenas a isso. Faria et al. (2014, p. 07), afirmam não ser possível resumir esta ciência a um único conceito, e que ela abarca dentro de si uma infinidade de elementos que a integram, suscitando dúvidas sobre a real quantidade de componentes.

Algumas das facetas do Marketing contemplam processos que otimizam a comunicação, técnicas de abordagem e ofertas que possuam valor não somente para os clientes, mas também para a sociedade como um todo. O Marketing, para além de uma ciência, é considerado um processo social que objetiva suscitar questionamentos sobre os meios pelos quais as pessoas obtêm aquilo que 
necessitam/desejam, fomentando a criação de novos serviços que atendam a esta demanda (FARIA et al., 2014, p. 07).

Kotler et al. (2017, p. 114) frisam que desejo é diferente de necessidade, e orientam que o produto, na maioria das vezes, é desenvolvido com base nestes; logo, a diferenciação entre eles torna-se essencial para promover estratégias de vendas. Em tempo, a necessidade não está relacionada a alguma vontade específica, ela existe por si só. Há necessidades fisiológicas, como dormir, respirar ou alimentar-se e as que não o são, como a de possuir moradia (FARIA et al., 2014, p. 10).

O desejo já se diferencia da necessidade por ter influência direta pela vontade do indivíduo que, por sua vez, pode ser moldada por costumes deste, tradições locais, questões relacionadas à cultura ou identidade daquele ser. À grosso modo, o desejo é o meio como o ser humano irá atender àquela necessidade. Por exemplo: Uma pessoa necessita se vestir, mas o tipo de roupa que ela escolherá está relacionado aos seus gostos pessoais, seus desejos (FARIA et al., 2014, p. 10).

A necessidade é um dos conceitos primordiais de Marketing, e para além destas exemplificadas pelos autores, é mister enfatizar a figura da Pirâmide de Maslow. Conforme Silva et al. (2017, p. 152), as necessidades relacionadas ao desenvolvimento pessoal ocupam o topo desta pirâmide. Em tempo, segue na figura 1 a representação gráfica da pirâmide. 
Figura 1: Pirâmide de Maslow

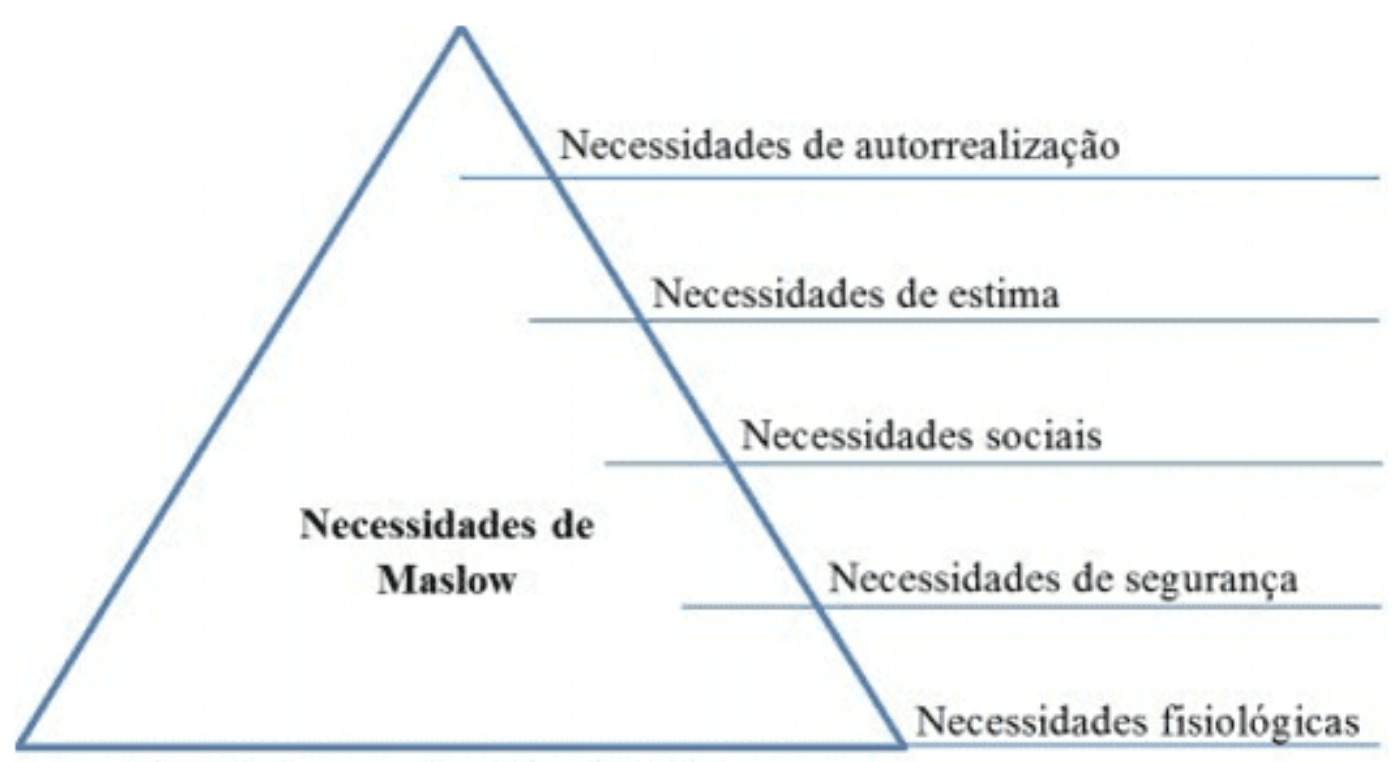

Fonte: Silva et al. (2017).

Tavares (2021) dialoga com Silva et al. (2017, p. 153) ao reproduzir a informação sobre a ordem de prioridades impostas na Pirâmide de Maslow, e exemplifica ainda alguns componentes de cada uma das necessidades distintas. Há que se frisar ainda que, conforme Tavares (2021) bem pontua, necessidades e desejos são componentes dos pressupostos centrais de Marketing, juntamente às demandas, produtos, troca, transações e mercados. Destes conceitos basilares, depreendem-se outros adicionais; há que se frisar também a figura dos chamados 4 "P"s, fatores determinantes para oferta do produto que se resumem a "produto, preço, praça e promoção".

Miranda (2017, p. 17-8) elucida os principais tipos de marketing existentes para fins de identificar quais as distintas formas de aplicação de cada um deles, uma vez que o resultado está condicionado a outros fatores, não somente ao tipo que foi empregado naquela ação. São tipos de Marketing: Direto e Indireto; de Relacionamentos; de Exclusividade; de Nicho; Sazonal; em Relações Públicas; de Fidelização; Outbound; Inbound; de Conteúdo; Promocional e de Guerrilha. 


\subsection{MARKETING DE SERVIÇOS}

Para Zeithaml et al. (2014), serviços são o bem intangível que objetivam satisfazer anseios mercadológicos. Marangoni (2015, p. 11) complementa este conceito, afirmando que desempenhar um serviço é desempenhar algum esforço para desenvolver uma ação a quem dele careça, envolvendo ou não algum bem relacionado ao serviço prestado.

Marangoni (2015, p. 14) preceitua também que os serviços elencam algumas características básicas, como: Intangibilidade, Inseparabilidade, Variabilidade e, ainda, que são impossíveis de se estocar por não serem palpáveis. Orienta, ainda, que existem diversas espécies de serviços, tal qual serviços profissionais, aqueles chamados de massa ou até mesmo customizados.

Marangoni (2015, p. 11), ao versar sobre a oferta e procura, dispõe que os anseios do consumidor movem o setor de serviços e, inclusive, impactam na criação de novas modalidades destes para atender estas demandas. Baseando-se nisto, é mister ater-se às particularidades das distintas formas de serviço, buscando métodos que levem em conta a singularidade daquilo que se oferta ao consumidor, considerando sempre como fator essencial a priorização das necessidades e desejos do público-alvo (LAS CASAS e GARCIA, 2015, p. 36).

Ainda naquilo que concerne aos serviços, Marangoni (2015, p. 74) doutrina que o know-how na execução deles é fator determinante quando se leva em conta as necessidades daqueles a quem eles se destinam. Las Casas e Garcia (2015, p. 356), orientam que é substancial investir na fidelização de clientes, estabelecendo para com eles um relacionamento sem qualquer posição de verticalidade, estando receptivo às demandas apresentadas pelo consumidor.

Perceber tendências de mercado e valer-se das mudanças para atrair clientes é basilar. Assim, conforme as doutas palavras de Marangoni (2015, p. 38), o Marketing de Serviços exige pleno conhecimento do público-alvo, uma vez que há inúmeras 
variáveis envolvidas que se pautam no tipo de serviço oferecido, e apenas deste modo seria possível aplicar as estratégias que forem cabíveis.

Kotler et al. (2017, p. 71) ratificam o supracitado posicionamento, uma vez que afirmam que, enquanto não adquirem um determinado produto/serviço, os consumidores são considerados alvos em potencial, e, em uma ótica tradicionalista de serviço ao cliente, quando finalmente decidem pela compra eles passam a equiparar-se à nobreza.

Saindo da perspectiva de serviço e passando para a de abordagem do atendimento, os consumidores passam a ser vistos como iguais. Agora, ao invés da posição de servidão com evidente verticalidade na relação onde eles imperavam, a prestadora de serviços passa a acolher suas demandas com oitiva ativa, respondendo a mesma conforme as condições que forem acordadas entre o consumidor e ela (KOTLER et al., 2017, p. 71).

Em suas origens, o Marketing de Serviços sequer possuía esta nomenclatura. Rocha e Platt (2015, p. 147) orientam que nas origens dessa ciência, ela era taxada como sendo a responsável por atrair novos clientes e manter os antigos, investindo na forma de se relacionar com cada qual. Destarte, é nítido que na essência deste tipo de marketing resta presente o estabelecimento de elos para com aquele a quem o serviço se destina. Esta herança foi auferida com o advento do Marketing de Serviços e continua existindo conforme o passar do tempo.

Baseando-se na realidade em que é mister conhecer o público para estabelecer relações através da comunicação, é imprescindível observar outra vez o ponto de partida, a questão norteadora: Como o Marketing de Serviços pode influenciar na captação de novos clientes?

FIA (2020) apresenta uma simples resposta ao questionamento suscitado, preceituando Marketing de Serviços como sendo o ramo de Marketing que age como uma ponte entre o quem presta os serviços e quem os consome, alcançando-Ihes por intermédio de táticas de comunicação para não somente garantir uma RC: 100657

Disponível em: https://www.nucleodoconhecimento.com.br/administracao/captacaode-novos 
contratação, mas também influenciar na formação da opinião do consumidor através de uma postura positiva, propagando impressões positivas acerca do que foi contratado. Pinheiro et al. (2012, p. 27) dialogam com a FIA (2020) ao ratificarem este pensamento.

Ambos os autores exprimem a ideia de que o Marketing de Serviços aprofunda o conhecimento basilar de desejos e necessidades do cliente que foram anteriormente abordados, para deste modo elaborar estratégias que se pautem diretamente naquele público-alvo em específico (PINHEIRO et al., 2012, p. 27; FIA, 2020).

Ademais, é necessário observar que, conforme foi abordado, existe a figura dos "P"s do Marketing. Já no de serviços, há que se ater a outros quatro elementos: Processo, pessoas, produtividade e palpabilidade. Dentre estes, Marangoni (2015, p. 27), ressalta a importância das pessoas e o investimento em colaboradores, uma vez que estão diretamente atrelados à execução dos serviços, possuindo impacto direto no entrosamento com o público-alvo, e, consequentemente, no feedback recebido pelos clientes, bem como na captação de outros.

\subsection{FERRAMENTAS DO MARKETING DE SERVIÇOS}

Neste tópico se abordarão as principais ferramentas do Marketing de Serviços, tais quais: Benchmarking, Servqual, Análise SWOT, Segmentação de Mercado, Sistema de Informações de Marketing e, sobretudo, o CRM, ou Customer Relationship Management.

\subsubsection{BENCHMARKING}

Para Madeira (1999, p. 364), há muitas teorias acerca do que seria o Benchmarking, e a mais aceita é que esta consiste no exercício de comparar os processos aplicados em uma organização com os de outras, as líderes mundiais. Compreendendo os processos de uma determinada companhia, reproduz-se 
naquela que for alvo desta técnica os comportamentos assertivos que puderem ser extraídos.

Ainda sobre o que Madeira (1999, p. 364) dispõe, do uso desta técnica advém duas vertentes a serem observadas: os benchmarks e os capacitadores. Respectivamente, dizem respeito às "medidas de desempenho comparativas" e os meios que a empresa paragonada utiliza para ter tal desempenho.

\subsubsection{SERVQUAL}

Gonçalves et al. (2017, p. 03) orientam que a escala Servqual diz respeito a comparação entre a expectativa que o cliente coloca nos serviços prestados e aquilo que ele efetivamente recebe, para fins de medir a qualidade daquilo que se oferta, fazendo-o através de perguntas objetivas com o intuito de inferir conclusões a partir da resposta que for dada pelo cliente.

Gonçalves et al. (2017, p. 03 apud FITZSIMMONS e FITZSIMMONS, 2010) determinam que esta ferramenta também serve para avaliar pontos importantes da qualidade dos serviços, como: "confiabilidade, responsividade, segurança, empatia e aspectos tangíveis".

\subsubsection{ANÁLISE OU MATRIZ SWOT}

Leite e Gasparotto (2018, p. 186) apontam que a Análise ou Matriz SWOT, também chamada como Análise FOFA, é a técnica responsável por promover a integração dos aspectos externos e internos da empresa, dividindo-os em categorias que compõem as quatro iniciais da nomenclatura "SWOT". "S" corresponde à Strengths, ou forças. "W" representa Weaknesses, as fraquezas. "O" é Opportunities, são oportunidades, e "T" representa Threats, as ameaças. Esta análise geralmente é utilizada juntamente com outras ferramentas de qualidade, ou, nas palavras de Leite e Gasparotto (2018, p. 186), compõe "um grupo com várias ferramentas estratégicas". 


\subsubsection{SEGMENTAÇÃO DE MERCADO}

Para Tavares et al. (2011, p. 108), a Segmentação de Mercado é a técnica de fracionar em pequenos grupos os componentes do mercado associados a um determinado produto ou serviço, sem levar em consideração os clientes, acrescendo-os por semelhanças. $O$ intuito desta segmentação é compreender diferenças no mercado, para enfim encontrar modos de lidar com elas ou, ainda, erradicá-las quando nocivas.

\subsubsection{SISTEMA DE INFORMAÇÕES DE MARKETING}

Khauaja e Campomar (2007, p. 26) orientam que o Sistema de Informações de Marketing, ou SIM, é a ferramenta responsável por reunir informações que virão a impactar no processo de planejamento de marketing.

\subsubsection{CUSTOMER RELATIONSHIP MANAGEMENT}

Para Kotler (2005, p. 124), o Customer Relationship Management, ou simplesmente CRM, é uma inovação tecnológica que simplifica a visualização dos potenciais clientes para uma abordagem mais assertiva quanto à oferta de serviços. Não necessariamente se aplica a qualquer empresa o uso desta ferramenta, posto que só é recomendável nos casos em que há grande fluxo de informações e variáveis.

Novello (2013, p. 06) relaciona o uso do CRM às técnicas de Marketing de Relacionamento, promovendo não apenas a captação de novos clientes, mas sim a manutenção dos antigos para ensejar a durabilidade deste elo, ou, conforme bem orienta a autora, saber "[...] exatamente quem é o seu cliente e do que ele gosta".

De Almeida (2013, p. 18) complementa o afirmado por Novello (2013) ao dizer que o CRM auxilia também a diferir quais são os tipos de clientes da empresa, separandoos em seis categorias distintas: os potenciais, os experimentadores, os compradores, os eventuais, os regulares e, por fim, os defensores. 
Potenciais (ou prospects) são aqueles que ainda não entraram no rol de clientes, apenas possuem um perfil que indica que os serviços da organização são interessantes a ele. Experimentadores são os clientes que já tiveram contato com a empresa e testam os serviços com fulcro em promoções e ofertas. Os compradores são aqueles que já adquiriram serviço e que não se manifestaram negativamente (DE ALMEIDA, 2013, p. 18).

Os clientes eventuais são aqueles que já utilizaram serviço da empresa e não possuem reclamações, mas não estabeleceram ainda a confiança, e em virtude disso mantém outras opções de serviços para contratar. Assim, quando a confiança dos eventuais é conquistada, passam a se tornar clientes regulares, isto é, aqueles que já conhecem os produtos e serviços e confiam no serviço prestado (DE ALMEIDA, 2013, p. 18).

Nesta linha, por fim, há os defensores. Ter muitos clientes com este perfil é um dos principais objetivos das técnicas de CRM, posto que eles já excederam a esfera de clientes regulares, chegando a se empenhar em propagar o nome da empresa e a formular, ocasionalmente, críticas construtivas (DE ALMEIDA, 2013, p. 18).

\section{MATERIAIS E MÉTODOS}

\subsection{PROCEDIMENTOS METODOLÓGICOS}

Esta pesquisa tem natureza descritiva e qualitativa, sendo desenvolvida através de pesquisa bibliográfica e de campo com fulcro na utilização de livros e blogs científicos.

O levantamento de dados iniciou-se em dezembro de 2020, priorizando dados dos últimos nove anos, isto é, pesquisas e livros realizados de 2012 em diante, acessados tanto por recurso manual quanto por fonte eletrônica. Posteriormente, deu-se o início do desenvolvimento da pesquisa, onde o conteúdo basilar foi elaborado, para posteriormente ser embasado por acervo bibliográfico físico, onde 
confirmaram-se e reiteraram-se as informações de cada tópico, bem como também se coletaram as referências bibliográficas.

Ademais, elaborou-se dentro da empresa Translins Transportes um diagnóstico organizacional, e a partir dele foi feito um estudo de caso que objetivou alinhar a teoria e a prática. Uma vez elaborado o estudo, fez-se a sugestão da aplicação do Marketing de Serviços na empresa em questão.

\subsubsection{QUANTO À NATUREZA}

Conforme as doutas palavras de Nascimento (2016, p. 02), é considerada aplicada a pesquisa que objetiva dar solução a um problema específico. A natureza de pesquisa aplicada resta evidente na elaboração do estudo de caso. Nascimento (2016, p. 03) orienta ainda que a pesquisa tem abordagem qualitativa quando se embasa na interpretação de fenômenos considerando as singularidades inerentes a cada questão, como ocorreu-se com os conceitos de marketing e sua multiplicidade de elementos componentes.

\subsubsection{QUANTO AOS FINS}

Em sua classificação quanto aos objetivos, o presente instrumento enquadra- se como sendo exploratório, uma vez que promove a aproximação para com o objeto de pesquisa no referencial teórico, para então valer-se da construção de hipóteses para auxílio no estudo de caso (NASCIMENTO, 2016, p. 04).

\subsubsection{QUANTO AOS MEIOS}

Em que pese a classificação sobre os meios, resta evidente que neste artigo empregou-se a pesquisa de campo, estudo de caso e produção bibliográfica (NASCIMENTO, 2016, p. 03). 


\subsection{CARACTERIZAÇÕES DA EMPRESA}

Enquadrada como sendo Empresa de Pequeno Porte, ou EPP, a Translins Transportes situa-se na Rua Úrsula Monteiro, 397 - Paraíso Tropical - Tarumã, é atuante no setor de logística, e busca através da realização de parcerias promover o transporte de todo tipo de carga, operando no Amazonas e em Roraima.

A meta organizacional da Translins Transportes é chegar ao patamar de benchmarking em serviços logísticos por seus clientes, parceiros e colaboradores, pautando-se em seus valores organizacionais: Pessoas, Serviços de Qualidade, Competência e Transparência.

A empresa conta com espaço de $400 \mathrm{~m}^{2}$ que se distribuem em garagem para frota, uma área administrativa e uma recepção para os clientes, em um layout que permite agilidade na execução das funções. Ela tem como clientes pessoas físicas que em determinados momentos necessitam do transporte de mercadorias, ou, ainda, empresas que utilizam do serviço para o transporte das suas mercadorias entre cidades, estados e países.

\section{RESULTADOS E DISCUSSÕES}

A criticidade mostrada no Gráfico 1 é definida pelo desempenho das áreas funcionais da Translins Transportes, exaradas no diagnóstico organizacional. 
Gráfico 1 - Áreas mais críticas da empresa

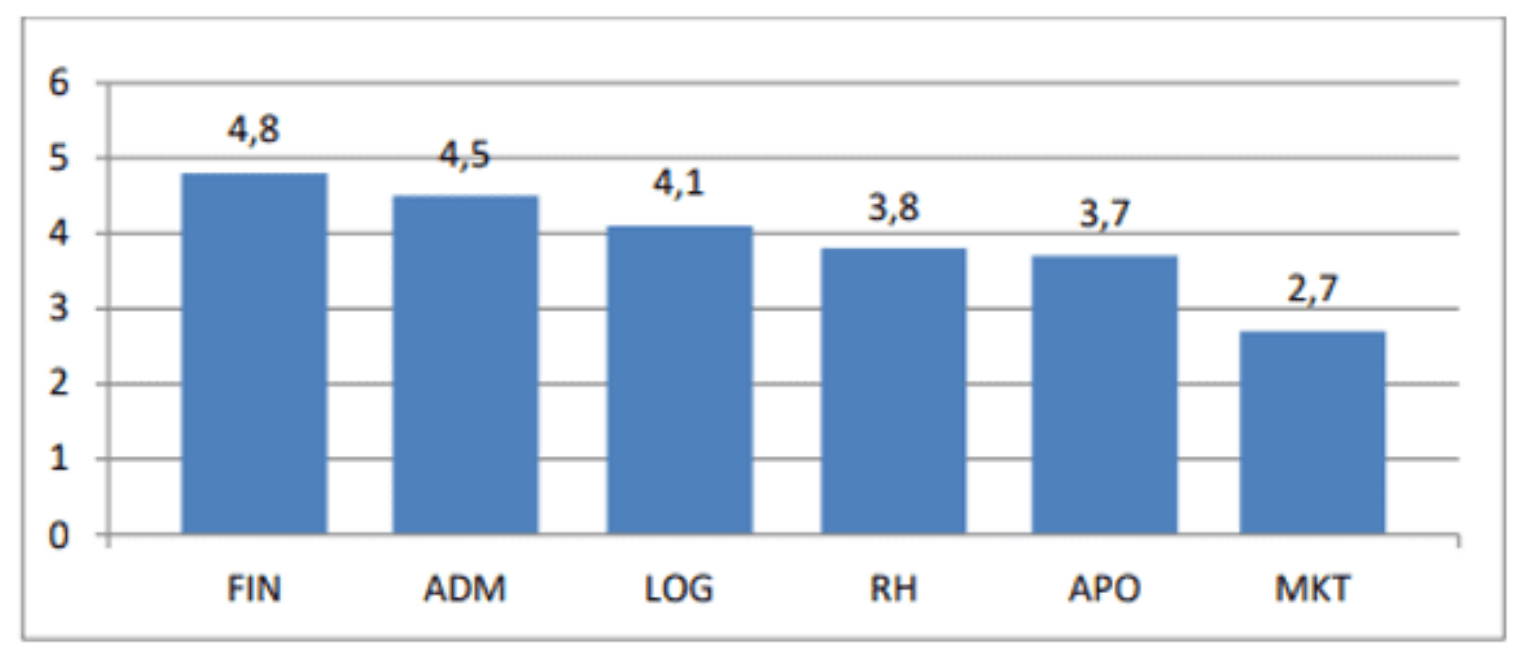

Fonte: Autoral (2021)

A área mais crítica é o setor de Marketing da empresa, que é quase inexistente. Para entender melhor a raiz dos problemas existentes com o setor de Marketing, segue na Tabela 1 a avaliação do setor. 
Tabela 1 - Avaliação do Marketing

\begin{tabular}{|c|c|c|c|c|c|c|}
\hline & ÁREA FUNCIONAL & & VEL OU & GRAU DE & AVALIAC & \\
\hline & MARKETING & $\begin{array}{l}\text { Ponto } \\
\text { muito }\end{array}$ & $\mid \begin{array}{l}\text { Ponto } \\
\text { forte 4 }\end{array}$ & $\begin{array}{l}\text { Ponto } \\
\text { médio } 3\end{array}$ & $\begin{array}{l}\text { Ponto } \\
\text { fraco } 2\end{array}$ & $\begin{array}{l}\text { Ponto } \\
\text { muito }\end{array}$ \\
\hline 1 & $\begin{array}{l}\text { A empresa possui uma efetiva força } \\
\text { com os clientes. }\end{array}$ & & & $x$ & & \\
\hline 2 & $\begin{array}{l}\text { A empresa é reconhecida pela sua } \\
\text { qualidade do serviço. }\end{array}$ & & $\mathrm{x}$ & & & \\
\hline 3 & $\begin{array}{l}\text { A empresa busca a fidelização do } \\
\text { cliente. }\end{array}$ & & & $x$ & & \\
\hline 4 & $\begin{array}{l}\text { A empresa controla satisfação dos } \\
\text { clientes. }\end{array}$ & & & & $\mathrm{x}$ & \\
\hline 5 & $\begin{array}{l}\text { A empresa está localizada em um } \\
\text { ponto de fácil acesso na cidade. }\end{array}$ & & $\mathrm{x}$ & & & \\
\hline 6 & $\begin{array}{l}\text { A organização apresenta políticas de } \\
\text { seguro para possiveis acidentes. }\end{array}$ & & & & $x$ & \\
\hline 7 & $\begin{array}{l}\text { Os equipamentos utilizados pela } \\
\text { empresa são de ultima geração. }\end{array}$ & & & & $x$ & \\
\hline 8 & $\begin{array}{l}\text { A organização possui um preço } \\
\text { competitivo no mercado. }\end{array}$ & & & $\mathrm{x}$ & & \\
\hline 9 & $\begin{array}{l}\text { A empresa aplica práticas de } \\
\text { flexibilidade em negociaçōes. }\end{array}$ & & & $x$ & & \\
\hline 10 & $\begin{array}{l}\text { Utiliza estratégias de Propaganda } \\
\text { nas redes sociais. }\end{array}$ & & & & & $x$ \\
\hline TOTAL & & - & 8 & 12 & 6 & 1 \\
\hline MÉDIA F & R GRAU (POR COLUNA) & 0 & 0,8 & 1,2 & 0,6 & 0,1 \\
\hline DESEMI & NHO DA ÁREA ( $(\Sigma)$ TOTAL & & & 2,7 & & \\
\hline
\end{tabular}

Fonte: Autoral (2021)

O setor de Marketing sem dúvidas é o mais crítico, sendo o ponto-alvo da proposta de intervenção. Dentre os fatores abordados no diagnóstico organizacional, conforme demonstrado na tabela acima, destaca-se algumas atribuições do setor de Marketing como, a falta de propaganda nas redes sociais, de bons equipamentos e de controle de satisfação dos clientes. Não há nenhum ponto marcado como muito forte, e é o único setor da empresa que conta com uma avaliação de "Ponto muito fraco". Deste modo, segue no próximo tópico a proposta de intervenção referente ao Marketing da Translins Transportes.

RC: 100657

Disponível em: https://www.nucleodoconhecimento.com.br/administracao/captacaode-novos 


\subsection{PROPOSTA DE INTERVENÇÃO}

Almejando compreender melhor as raízes dos problemas da empresa, fez-se uso do Diagrama de Ishikawa. Este consiste em uma ferramenta analítica que busca novas fontes de variações em processos a fim de dar direcionamento à erradicação das causas em potencial que podem gerar efeitos indesejados. Desta forma, o Diagrama de Ishikawa também é popularmente conhecido como Diagrama Espinha de Peixe devido ao seu curioso formato, onde, no eixo horizontal, encontra-se o efeito que se quer erradicar e nas laterais as possíveis causas, conforme disposto na Figura 2.

Figura 2 - Diagrama de Ishikawa

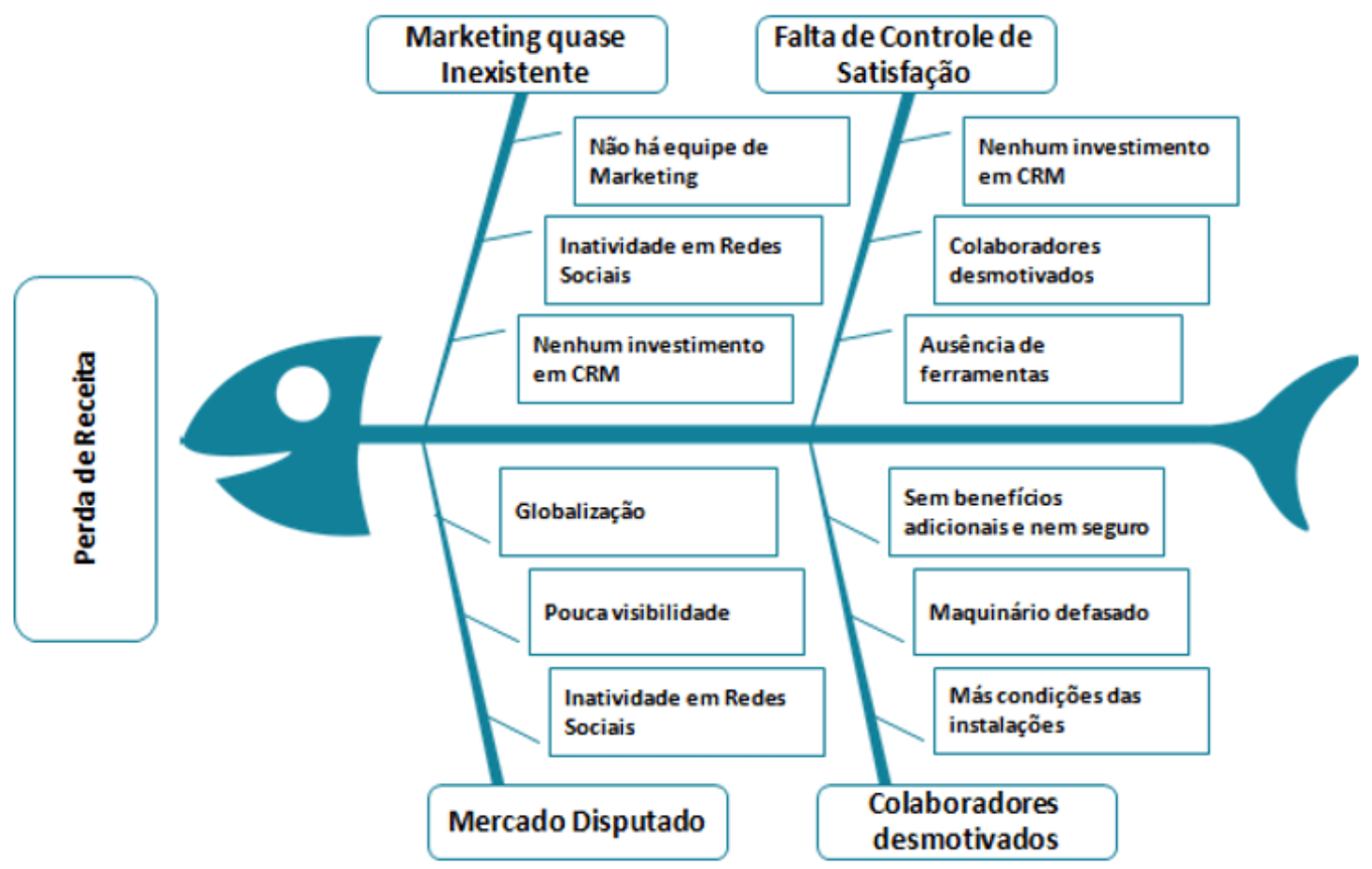

Fonte: Autoral (2020)

A causa "Mercado Disputado" é impossível de se alterar com ações internas, sendo necessário traçar ações que destaquem a empresa para soar mais atrativa ao consumidor, erradicando os fatores "Pouca Visibilidade" e "Inatividade em Redes Sociais", correlacionando-se, portanto, com a causa "Marketing quase inexistente", uma vez que já restou evidente na revisão bibliográfica que é mister o uso de RC: 100657

Disponível em: https://www.nucleodoconhecimento.com.br/administracao/captacaode-novos 
técnicas de CRM tanto para captação dos clientes quanto para manutenção daqueles que já contrataram o serviço.

A causa "Falta de controle de satisfação" também se correlaciona com a causa "Marketing quase inexistente", uma vez que faz parte do Marketing de Serviços relacionado à comunicação eficiente para com os clientes, englobando ainda o Feedback pelos serviços prestados. Conforme abordado anteriormente, Marangoni (2015, p. 74) orienta que a qualidade na prestação dos serviços é essencial, o que é um ponto positivo, posto que a empresa é reconhecida por sua aptidão.

Sobre a causa "Colaboradores desmotivados", observa-se que estes são parte essencial para todos os setores da empresa, e são exordiais para manter a qualidade dos serviços prestados e conseguir contatar os clientes para efetivar a aplicabilidade do Marketing de Serviços. Baseando-se nestes fatos, foram eleitas as causas "Marketing quase inexistente" e "Colaboradores desmotivados" para formular uma proposta de intervenção.

As causas "Não há equipe de Marketing" e "Nenhum Investimento em CRM" têm evidente nuance com a causa "Inatividade em redes sociais", sendo nítida a relação de causa e efeito entre estas. Considerando o impacto enorme que as redes sociais têm hodiernamente, é necessária a sua utilização para se alcançar a visibilidade necessária para competir em iguais condições com a concorrência (KOTLER et al. 2017).

A causa "Colaboradores desmotivados" é relevante para o efeito "Marketing quase inexistente", uma vez que na aplicação das técnicas de Marketing de Serviços é imprescindível contar com todos os colaboradores da empresa, que devem estar alinhados quanto à missão, visão e valores desta.

Os funcionários são responsáveis por estabelecer a comunicação eficiente com o consumidor, para garantir a venda e receber o feedback referente ao produto, relacionando-se então com a causa "Falta de controle de satisfação". Analisando "Colaboradores desmotivados" enquanto efeito, é notório que existem falhas no RC: 100657

Disponível em: https://www.nucleodoconhecimento.com.br/administracao/captacaode-novos 
sistema da empresa no que se refere a eles. A causa "Maquinário defasado" acaba por impactar na desmotivação dos colaboradores por exigir que empreguem mais esforço para realização de suas tarefas, além de atingir a agilidade na prestação dos serviços.

A causa "Más condições das instalações" é resultado da soma do pífio maquinário com as instalações operacionais, que não se encontram em perfeito estado no que diz respeito à limpeza e organização, conforme restou constatado durante o diagnóstico. A causa "Não há benefícios adicionais e nem seguro" por si só já possuem relevância na situação atual. Os colaboradores trabalham desmotivados, e é necessário incentivar e satisfazer as necessidades deles para que exerçam eficientemente suas funções.

Deste modo, compreendidas as causas e efeitos, é mister elaborar o quadro de proposta de melhorias baseado nos problemas percebidos, sendo dividida em duas etapas: A primeira versa sobre sugestões de investimentos em contratações, enquanto a segunda é sobre CRM. Em tempo, sobre a primeira etapa, segue o quadro de proposta de melhorias na Tabela 2.

Tabela 2: Quadro de Proposta de Melhorias Investimento em Contratações

\section{QUADRO DAS PROPOSTAS DE MELHORIA}

\begin{tabular}{|c|c|c|c|}
\hline $\begin{array}{l}\text { Oportunidade } \\
\text { Melhoria }\end{array}$ & de & Proposta & Efeito Esperado \\
\hline $\begin{array}{l}\text { Investimento } \\
\text { Marketing }\end{array}$ & em & $\begin{array}{l}\text { Contratação de uma equipe } \\
\text { especializada }\end{array}$ & $\begin{array}{l}\text { Ampliar a carteira de } \\
\text { clientes, } \\
\text { aumento na receita. }\end{array}$ \\
\hline $\begin{array}{l}\text { Investimento } \\
\text { Condições } \\
\text { Trabalho }\end{array}$ & $\begin{array}{r}\text { nas } \\
\text { de }\end{array}$ & $\begin{array}{l}\text { Melhorar o maquinário da } \\
\text { empresa, contratar uma } \\
\text { equipe de limpeza. }\end{array}$ & $\begin{array}{l}\text { Aumentar a satisfação dos } \\
\text { colaboradores. }\end{array}$ \\
\hline $\begin{array}{l}\text { Investimento } \\
\text { Satisfação }\end{array}$ & $\begin{array}{r}\text { na } \\
\text { dos }\end{array}$ & $\begin{array}{l}\text { Ofertar benefícios atrativos } \\
\text { e melhores condições de }\end{array}$ & $\begin{array}{l}\text { Colaboradores satisfeitos } \\
\text { tendem a apresentar melhor }\end{array}$ \\
\hline
\end{tabular}

RC: 100657

Disponível em: https://www.nucleodoconhecimento.com.br/administracao/captacaode-novos 
Colaboradores

trabalho.

desempenho.

Fonte: Autoral (2021)

Partindo deste quadro de proposta de melhorias, utilizou-se, portanto, a ferramenta $5 \mathrm{~W} 2 \mathrm{H}$ para traçar a forma de execução da proposta de intervenção, permitindo visualizar melhor as figuras responsáveis pela execução de cada ação, conforme demonstrado na Tabela 3.

Tabela 3: 5W2H - Proposta de Intervenção

\begin{tabular}{|c|c|c|c|c|c|c|}
\hline \multicolumn{7}{|c|}{ PLANO DE AÇÃO - 5W2H } \\
\hline O Quê? & Como? & Quando? & \begin{tabular}{|l|} 
Onde? \\
\end{tabular} & Por quê? & Quem? & Quanto \\
\hline $\begin{array}{l}\text { Investimento } \\
\text { em Marketing }\end{array}$ & $\begin{array}{l}\text { Contratando uma } \\
\text { equipe de } \\
\text { Marketing }\end{array}$ & Imediatamente & $\begin{array}{l}\text { Sede da } \\
\text { empresa }\end{array}$ & $\begin{array}{l}\text { Para executar técnicas de } \\
\text { Marketing de Serviços. } \\
\text { Captar novos clientes e } \\
\text { fidelizar os existentes. } \\
\text { Promover o controle de } \\
\text { perda de clientes. }\end{array}$ & $\begin{array}{l}\text { Departamento } \\
\text { de } \mathrm{RH}\end{array}$ & $\begin{array}{c}\mathrm{RS} \\
2.807 / \\
\text { mês* }\end{array}$ \\
\hline $\begin{array}{c}\text { Investimento } \\
\text { nas Condições } \\
\text { de Trabalho }\end{array}$ & $\begin{array}{c}\text { Melhorando o } \\
\text { maquinário e } \\
\text { contratando uma } \\
\text { equipe de limpeza }\end{array}$ & Imediatamente & $\begin{array}{c}\text { Área } \\
\text { operacional } \\
\text { da empresa }\end{array}$ & $\begin{array}{l}\text { Para melhorar o } \\
\text { desempenho dos } \\
\text { colaboradores e, } \\
\text { consequentemente, a } \\
\text { satisfação dos clientes. }\end{array}$ & $\begin{array}{c}\text { Setor } \\
\text { Administrativo } \\
\text { / Departamento } \\
\text { de } \mathrm{RH}\end{array}$ & $* *$ \\
\hline $\begin{array}{c}\text { Investimento } \\
\text { na Satisfação } \\
\text { dos } \\
\text { Colaboradores }\end{array}$ & $\begin{array}{c}\text { Investindo em } \\
\text { condições de } \\
\text { trabalho e } \\
\text { benefícios laborais }\end{array}$ & Imediatamente & $\begin{array}{l}\text { Em toda } \\
\text { empresa }\end{array}$ & $\begin{array}{c}\text { Para melhorar o } \\
\text { desempenho dos } \\
\text { colaboradores e, } \\
\text { consequentemente, a } \\
\text { satisfação dos clientes. }\end{array}$ & $\begin{array}{l}\text { Departamento } \\
\text { de } \mathrm{RH}\end{array}$ & $* * *$ \\
\hline \multicolumn{7}{|c|}{$\begin{array}{l}\text { * Para este valor consideraram os dados de VAGAS (2021) [1] e [2]. Utilizou-se a média nacional para contratação do } \\
\text { profissional de marketing e o valor de remuneração para um estagiário de marketing iniciante. }\end{array}$} \\
\hline \multicolumn{7}{|c|}{$\begin{array}{l}\text { ** Como há maquinário específico, o valor do custo total só pode ser calculado após a reunião com os profissionais } \\
\text { responsáveis. }\end{array}$} \\
\hline
\end{tabular}

Fonte: Autoral (2021)

Para a efetiva execução da primeira parte da proposta de intervenção, optou- se pela divisão em três fases: reunião com as equipes pertinentes para elaborar o levantamento dos custos e efetuar pesquisa mercadológica; reunião com os gerentes e diretor para pleitear aval sobre a proposta de intervenção; E, em caso de resposta positiva, no segundo passo, pôr em prática as mudanças solicitadas.

RC: 100657

Disponível em: https://www.nucleodoconhecimento.com.br/administracao/captacaode-novos 
Sendo a segunda parte da proposta de intervenção e levando em conta a já justificada necessidade de implementação do CRM, elaborou-se ainda uma sugestão de apresentação dele à gerência e diretoria, conforme demonstram os passos dispostos no Fluxograma 1.

Fluxograma 1: Proposta de Intervenção no CRM

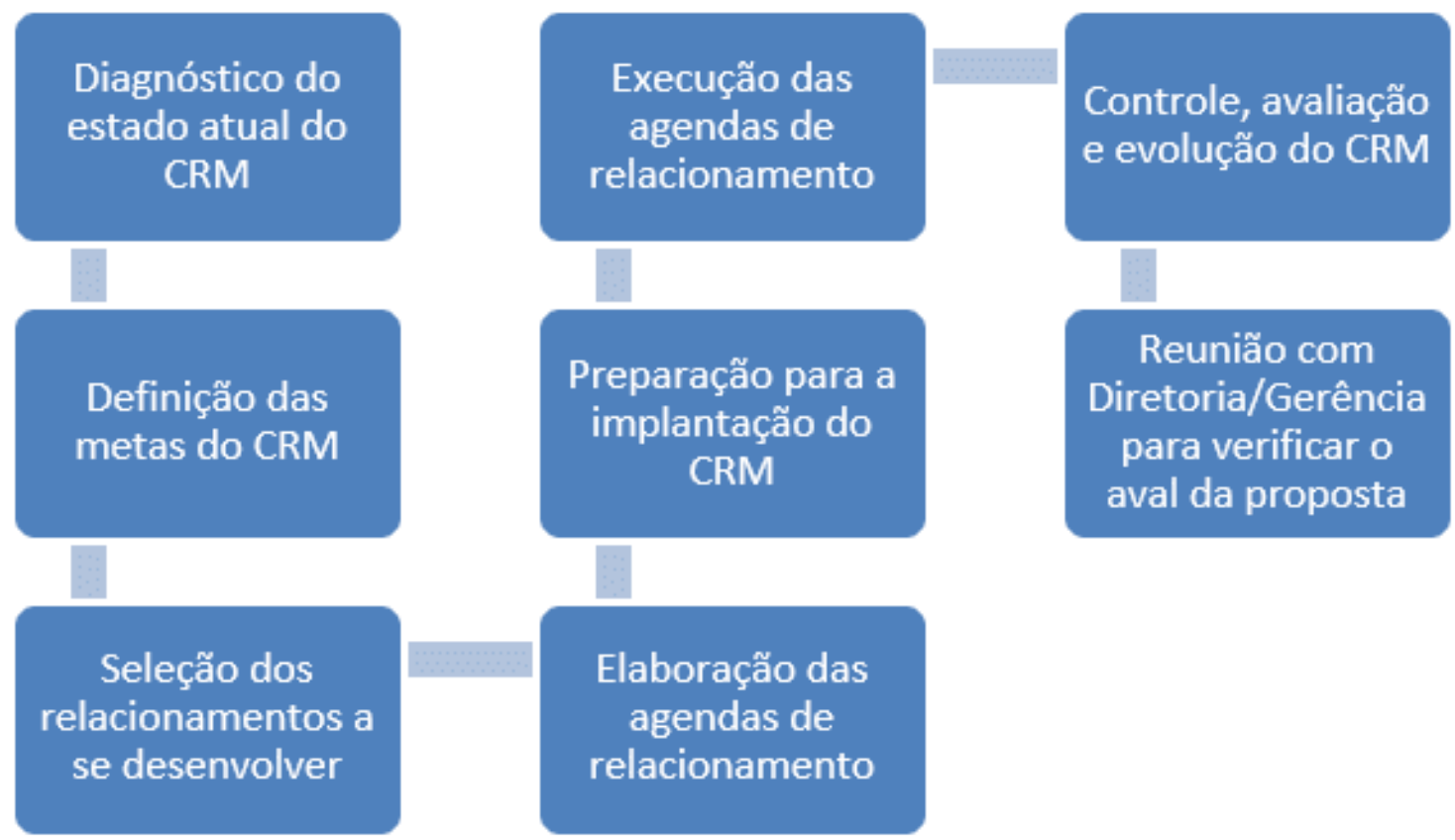

Fonte: Autoral (2021)

\subsubsection{PASSO 1: DIAGNÓSTICO DO ESTADO ATUAL DO CRM}

O CRM sequer existe atualmente na empresa, conforme restou evidente no diagnóstico organizacional. Logrando êxito com a contratação da equipe de Marketing, seria um dos primeiros pontos a se trabalhar, para fins de obter o supracitado controle de fluxo de clientes.

RC: 100657

Disponível em: https://www.nucleodoconhecimento.com.br/administracao/captacaode-novos 


\subsubsection{PASSO 2: DEFINIÇÃO DAS METAS DO CRM}

Definiram-se metas simples para o CRM, como estabelecer controle do fluxo de clientes para poder catalogá-los conforme o tipo (eventuais, potenciais, experimentadores...); alcançar mais clientes e, por fim, aumentar a receita.

\subsubsection{PASSO 3: SELEÇÃO DOS RELACIONAMENTOS A SE DESENVOLVER}

Os relacionamentos a serem enfatizados serão, sobretudo, com os clientes potenciais com objetivo de aumentar a carteira e também os clientes regulares, de modo a ensejar que se transformem em defensores. Os clientes eventuais e experimentadores também terão uma cultura de relacionamento estabelecida, mas em menor escala enquanto comparados aos regulares e potenciais.

\subsubsection{PASSO 4: ELABORAÇÃO DAS AGENDAS DE RELACIONAMENTO}

Para elaboração das agendas considera-se a jornada diária de oito horas de trabalho, levando também em consideração os horários de pico das redes sociais para a captação de clientes neste nicho. Também se reserva datas e horários quinzenalmente para contato com os clientes alvo da proposta.

\subsubsection{PASSO 5: PREPARAÇÃO PARA IMPLANTAÇÃO DO CRM}

A preparação para a implantação consistirá, especialmente, em determinar quais serão os meios de contato com os clientes para utilizar, quais serão os dias da semana destinados a cada público dentre os tipos de clientes selecionados, entre outros detalhes inerentes. 


\subsubsection{PASSO 6: EXECUÇÃO DAS AGENDAS DE RELACIONAMENTO}

A execução das agendas consiste no estabelecimento do relacionamento propriamente dito, isto é, contatar os prospects através dos principais nichos e estabelecer uma cultura de feedback com eles quando não forem convertidos em clientes. Para os clientes que já fazem uso recorrente dos serviços da empresa, a sugestão é fomentar quinzenalmente o relacionamento com eles, pedindo feedbacks acerca do serviço prestado. Na execução, também seria viável estudar junto ao setor financeiro algumas ofertas e descontos diferenciados para estes clientes, objetivando fidelizá-los.

Estas ofertas e descontos também poderiam aplicar-se aos demais clientes, através dos quais se sugere estabelecer contato mensalmente por meio de contato assinalado por eles como sendo mais conveniente, de modo a fazer com que se lembrem da empresa e dos serviços por ela prestados.

\subsubsection{PASSO 7: CONTROLE, AVALIAÇÃO E EVOLUÇÃO DO CRM}

O controle do CRM seria elaborado pela, ainda não existente, equipe de Marketing, pleiteando que se siga um padrão positivo no alcance das metas. A avaliação se dará pelo cumprimento das metas, estabelecendo-se a frequência mensal para medir os avanços. A avaliação da evolução será feita de modo a comparar os dados do mês anterior com o novo mês, para extrair o percentual de aumento ou redução de clientes que buscaram a empresa, ou, ainda que não tenham utilizado mais os serviços.

\section{CONSIDERAÇÕES FINAIS}

Através deste estudo foi possível compreender conceitos básicos como o de Marketing propriamente dito, Marketing de Serviços, e, principalmente, compreender como ele influencia na captação de novos consumidores, o que ocorre através do relacionamento trabalhado por colaboradores de uma determinada empresa para 
com o cliente, que passa a se sentir acolhido com a receptividade aos problemas que apresenta, fazendo uso de CRM.

Como a pesquisa objetivou inicialmente responder "Como o Marketing de Serviços impacta na captação de novos clientes?", através do fomento da interação proposta pelo emprego de marketing de serviços é possível obter a supracitada mitigação da verticalidade na relação entre cliente e prestador de serviços, aumentando a receptividade às demandas do cliente através da escuta ativa. Assim sendo, o cliente é abordado de modo a induzir a contratação do serviço.

É possível inferir que este objetivo foi atingido com sucesso, considerando-se que chegou a conclusão de que a Gestão de Relacionamento com o público é a chave para tal.

Outro dos objetivos inicialmente abordados foi obter a compreensão de como estas técnicas se aplicariam à Translins Transportes. É mister destacar que, por ser uma empresa prestadora de serviços de logística, estas técnicas se aplicariam perfeitamente à empresa em questão, e, ainda, em virtude de sua necessidade, posto que sequer há setor de Marketing. Não há controle do fluxo de clientes, tampouco do relacionamento com eles, o que justifica por si só a relevância do CRM para a empresa.

A empresa não investe em novas formas de captar o consumidor, como, por exemplo, as redes sociais. A globalização é o principal fator-chave para desencadear a competitividade do mercado que se possui atualmente, motivo este que implica na necessidade obrigatória de se ater às novas tecnologias a fim de estar em condições pares com os concorrentes em geral.

Identificado o Marketing como principal problema no diagnóstico organizacional, o Marketing de Serviços apresentou-se como sendo uma técnica que abarca a possibilidade de desequilibrar a disputa pelo consumidor, pois com auxílio dele, a empresa se diferencia da concorrência para influenciar o momento da tomada de decisão do público-alvo.

RC: 100657

Disponível em: https://www.nucleodoconhecimento.com.br/administracao/captacaode-novos 
Por fim, a proposta de CRM como mecanismo para promover o já tão abordado relacionamento restou-se favorável, sendo a melhor sugestão possível para o momento atual em que a empresa vive. No diagnóstico organizacional foi atestado que a empresa não tem problemas financeiros, mas como houve a sugestão de investimentos durante a proposta de intervenção, é necessário que haja o retorno financeiro delas para compensar o valor gasto, sendo justamente este o objetivo pleiteado nesta proposta.

\section{REFERÊNCIAS}

DE ALMEIDA, T. M. Aplicação do conceito de CRM na pequena empresa com o auxílio da Tecnologia da Informação. Universidade Regional do Noroeste do Estado do Rio Grande do Sul, 2013. Disponível em: <https://bibliodigital.unijui.edu.br:8443/xmlui/bitstream/handle/123456789/2034/TCC_ Vers\%C3\%A30\%20Final.pdf?sequence=1\&isAllowed=y>. Acesso em: 30 de Setembro de 2021.

FARIA, C. et al. Marketing Aplicado. 1를. Porto Alegre: Bookman. 2014.

FIA. Marketing de Serviços: o que é, como fazer estratégias de sucesso. Fundação Instituto de Administração, 2020. Disponível em: < https://fia.com.br/blog/marketing-de-servicos/>. Acesso em: 26 de Agosto de 2021.

GONÇALVES, W. de S. et al. Aplicação do método Servqual: Um estudo de satisfação do cliente em um estacionamento de veículos leves. In: XXXVII Encontro Nacional de Engenharia de Produção, 2017. Disponível em: <http://www.abepro.org.br/biblioteca/TN_STO_239_389_34706.pdf>. Acesso em 30 de Setembro de 2021.

KHAUAJA, D. M. R.; CAMPOMAR, M. C. O sistema de planejamento de Marketing: Em busca de vantagem competitiva. Rev. Gestão da Tecnologia. V. 4. № 1. 2007.

Disponível em: 
<https://www.scielo.br/j/jistm/a/t3dJZQFvqL8K4jQFy5tBxDM/?format=pdf\&lang=pt>. Acesso em 30 de Setembro de 2021.

KOTLER, P. Administração de marketing. 12 ${ }^{\mathrm{a}}$ Ed. São Paulo: Prentice Hall; 2005.

KOTLER, P. et al. Marketing 4.0: Do tradicional ao digital. 1ª Ed. Rio de Janeiro: Sextante. 2017.

LAS CASAS, A. L.; GARCIA, M. T. Estratégias de marketing para varejo. São Paulo: Novatec, 2015.

LEITE, M. S. R.; GASPAROTTO, A. M. S. Análise SWOT e suas funcionalidades: O autoconhecimento da empresa e sua importância. Rev. Interface Tecnológica. FATECTQ. 2018.2 Disponível em: $<$ https://revista.fatectq.edu.br/index.php/interfacetecnologica/article/download/450/30 9/2121>. Acesso em 30 de Setembro de 2021.

MADEIRA, P. J. Benchmarking: A arte de copiar. Jornal do Técnico de Contas e da Empresa. № $411.41999 . \quad$ Disponível em: $<$ https://repositorio.jpcb.pt/bitstream/10400.11/964/1/Benchmarking.pdf>. Acesso em 30 de Setembro de 2021.

MARANGONI, S. Marketing de Serviços. 1ª Ed. Rio de Janeiro: SESES. 2015.

MIRANDA, H. P. Tipos de marketing. 9. ed. Revista Gestão em Foco, 2017. Disponível em: <https://portal.unisepe.com.br/unifia/wpcontent/uploads/sites/10001/2018/06/003_artigo_hugo_pedroso_miranda.pdf>. Acesso em: 27 de Agosto de 2021.

NASCIMENTO, F. P. do. Classificação da Pesquisa. Natureza, métodos ou abordagem metodológica, objetivos e procedimentos. In: Metodologia da Pesquisa Científica: teoria e prática - como elaborar TCC. Brasília: Thesaurus, 2016 
NOVELLO, A. P. Os benefícios proporcionados pelo CRM (Customer Relationship Management) nas pequenas empresas. Escola Superior de Administração, Marketing e Comunicação. 2013. Disponível em: <http://faculdadeanglo.com.br/wp-content/uploads/2014/05/Andr\%C3\%A9iaADM.pdf>. Acesso em: 30 de Setembro de 2021.

PINHEIRO, L. et al. Metodologia para captação de novos clientes: Estudo de caso em uma empresa pontagrossense de assessoria em comércio exterior. 14. ed. Revista Innovare, 2012.

ROCHA, R. A. da; PLATT, A. A. Administração de marketing. 3. ed. Florianópolis: Departamento de Ciências da Administração, 2015. Disponível em: $<$ https://ead2.moodle.ufsc.br/pluginfile.php/187459/mod_resource/content/6/admmarketing-3ed-alterado.pdf>. Acesso em: 26 de Agosto de 2020.

SILVA, V. L. da. et al. Análise da motivação de pessoas: Um estudo baseado em princípios da Hierarquia de Necessidades de Maslow. Revista FOCO. ISSN: 1981-223X. Vol. 10, № 2. 2017.

TAVARES, F. Marketing: Conceitos, tipos, objetivos e análise de desempenho. Disponível em: <http://www.fredtavares.com.br/marketing_conceitos_tipos.htm>. Acesso em 26 de Agosto de 2021.

TAVARES, M. C. et al. Segmentação de mercado, diferenciação de produtos e a perspectiva da antropologia do consumo. Rev. Gestão e Tecnologia. V. 11. № 1. 2011.

Enviado: Outubro, 2021.

Aprovado: Novembro, 2021. 